\title{
MINIMAL INVASIVE DYNAMIC HIP SCREW FIXATION FOR INTERTROCHANTERIC FRACTURES OF FEMUR
}

\author{
Dr. Prakriti Raj Kandel ${ }^{1,}$ Dr. Laxmi Pathak², Dr. Gyaneshwar Prasad Singh³ ${ }^{3}$ Dr. Rajiv Baral ${ }^{4}$
}

\begin{abstract}
INTRODUCTION:

Good results have been achieved consistently with compression hip screw fixation for stable intertrochanteric femur fractures by conventional method. Thus, this present study was conducted to find out the outcomes for such hip fracture fixation with minimal invasive technique.
\end{abstract}

\section{MATERIALS AND METHOD:}

This retrospective study was carried out by collecting the records of 66 adult patients with stable intertrochanteric femur fracture managed by Dynamic Hip Screw (DHS) fixation with minimal invasive technique under Spinal Anaesthesia and Epidural Analgesia in Universal College of Medical Sciences and Teaching Hospital (UCMSTH) over a period of 3 years. The patients were in follow up visits for 1 year postoperatively. Operating time, blood loss, decrease in haemoglobin level, analgesic demand, length of hospital stay, fracture union time, early and delayed complications and functional outcome were recorded.

\section{RESULTS:}

This study showed less operative time, less blood loss and less reduction in mean haemoglobin value postoperatively when compared with baseline values. Though complications like pain, stitch infection at surgical site and UTI was seen in few patients, all patients were mobilized within $2^{\text {nd }}$ postoperative day with less rescue analgesic demand and shorter duration of hospital stay of only 8.23 days. However, plate breakage, nonunion, implant cut out, joint infection, delayed union and varus deformity was not observed in any of these patients. Moreover, Harris Hip Score showed good functional outcome.

\section{CONCLUSION:}

Fixation of DHS with minimal invasive technique for stable hip fracture has good functional outcome in cost effective way with fewer incidences of complications.

KEYWORDS: Intertrochanteric fracture, Dynamic Hip Screw, Minimal invasive technique for fixation of DHS

1. Assistant Professor of Department of Orthopedics, Universal College of Medical Sciences \& Teaching Hospital, Bhairahawa, Nepal

2. Associate professor, Department of Anesthesia, Universal College of Medical Sciences \& Teaching Hospital, Bhairahawa, Nepal

3. Prof. of Orthopedics Universal College of Medical Sciences \& Teaching Hospital, Bhairahawa, Nepal

4. Asst. Prof. of Orthopedics, Universal College of Medical Sciences \& Teaching Hospital, Bhairahawa, Nepal

\author{
For correspondence: \\ Dr. Prakriti Raj Kandel \\ Assistant Professor, Department of Orthopaedics, \\ Universal College of Medical Sciences \&Teaching Hospital, \\ Bhairahawa, Nepal \\ E-mail:pratul22@gmail.com
}




\section{INTRODUCTION:}

Hip fractures are leading cause of death and disability among the elderly. Proximal femoral fracture accounts $30 \%$ of all hospital admissions with mortality of $15-20 \%$ worldwide. Among these, trochanteric fractures are around four times more with female predominance. Treatment goals for these populations include early rehabilitation, restoration of the anatomic alignment of the proximal part of femur and maintenance of fracture reduction. ${ }^{1-4}$ Though resistance augmented Baixauli plates, Medroff plates, trochanteric stabilizing plates, percutaneous compression plates and intra medullary devices are focused on unstable inter-trochantric fracture, it is now almost universally accepted that internal fixation is the best method in which fixation with Dynamic Hip Screw (DHS) is considered as the standard one. ${ }^{5-9}$ In the last decade, minimal invasive DHS (MIDHS) technique offered a better outcome compared to conventional approach, while maintaining equal fixation stability. The experimental basis of minimal invasive surgery is based on the fact that nutrient artery gives $2 / 3^{\text {rd }}$ of the blood supply to the bone, and $1 / 3^{\text {rd }}$ comes from the periosteum inflow. ${ }^{3}$

This study was conducted to ascertain the short term safety and effectiveness of a standardized DHS device inserted using minimally invasive technique in Nepalese patients.

\section{MATERIAL AND METHODS:}

This is a retrospective randomized study of 66 patients who underwent MIDHS technique for intertrochanteric fracture from $1^{\text {st }}$ December 2012 to $31^{\text {st }}$ January 2015 in Universal College of Medical Science \& Teaching Hospital, Bhairahawa, Nepal with at least one year of follow up. All closed intertrochanteric fractures with BOYD \& GRIFFIN classification, American Society of Anesthesiologist (ASA) physical status I and II were included in this study whereas patients with poly-trauma, pathological fracture, compound fracture, failed closed reduction on fracture table and ASA more than II were excluded. After taking written informed consent from patient and fitness given for anesthesia, all patients were pre-medicated with Tablet Lorazepam $1 \mathrm{mg}$ a night before surgery and then Nil per Oral. All patients were operated upon under Spinal Anesthesia in a supine position on a radiolucent traction table. After sensitivity test, a single prophylactic anti-biotic cefuroxime 1 gram intravenously was given 15 minutes before skin incision.

The skin over the hip was properly painted and draped by placing the towel clips away to prevent superimpose on the fracture on subsequent imaging. The $\mathrm{C}$-arm was also draped separately. A guide wire mounted in 135-degree guide plate was placed over anterior aspect of hip and checked in image intensifier in AP view (Figure 1). Plate was made aligned with the lateral border of femur and guide wire was aligned in lower half of femoral neck and head. Entry point of guide wire was marked in lateral aspect of thigh. Skin incision about 4-5 cm was made. Fascia Lata and Vastus Lateralis were incised by diathermy to minimize blood loss. Guide wire was inserted from lateral border of femur below $2.5 \mathrm{~cm}$ from trochanteric flair (Figure 2). Correct placement of guide-wire was checked with image intensifier in AP and lateral views (Figure $3 \& 4$ ). Another parallel guide pin was inserted to provide temporary stability for unstable fractures, in which the reduction can be lost if the guide pin backs out after reaming.

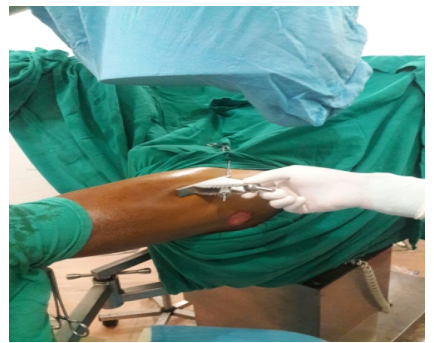

Figure 1: Incision site

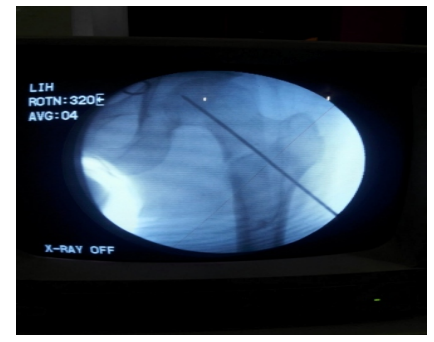

Figure 3: Guide wire placement (AP view)

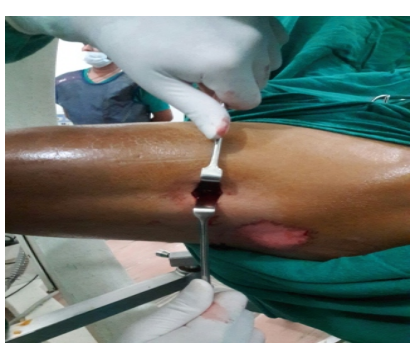

Figure 2: Guide wire entry point

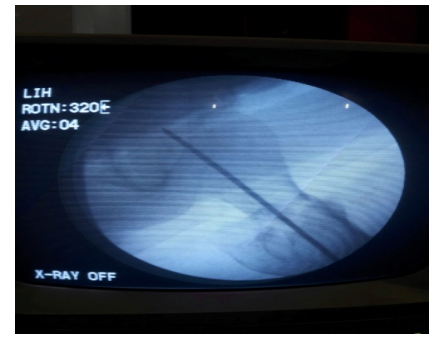

Figure4: Guide wire placement (lateral view)
After insertion of guide pin, it was measured and advanced 5 $\mathrm{mm}$ more into the subchondral bone, reamed adequately and a lag screw was chosen. Hip screw was then inserted (Figure 5, 6 \& 7). After removal of guide-wire, three-hole barrel plate was inserted facing it laterally through the wound and turned 180 degree introducing over hip screw (Figure 8). Plate was then fixed with femur shaft with three cortical screws. Compression screw was inserted (Figure 9). Fascia and subcutaneous tissues were sutured with absorbable suture and skin was closed with non-absorbable suture (Figure 10).

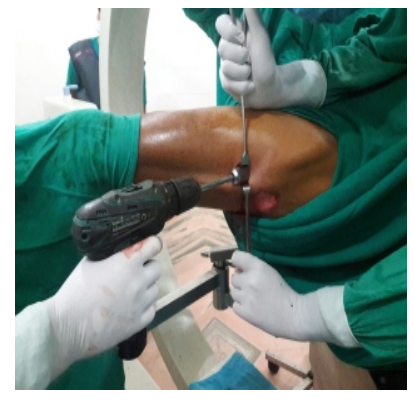

Figure 5: Reaming with Reamer

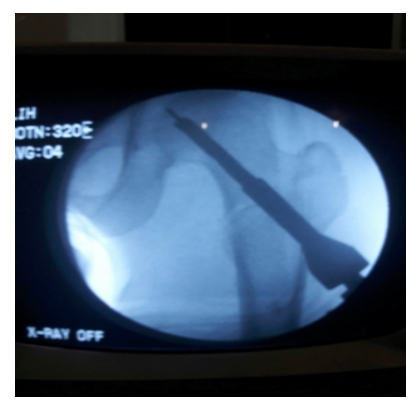

Figure 6: Reaming with desire length 


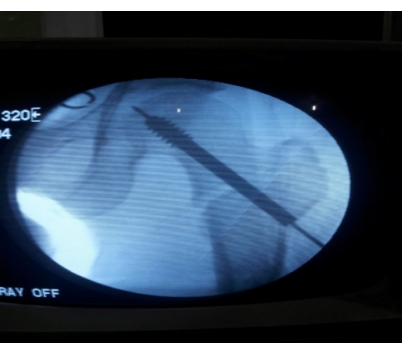

Figure 7: Insertion of hip screw

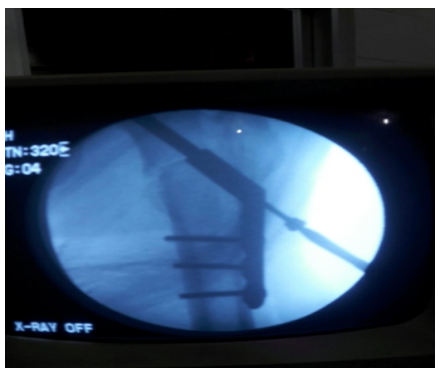

Figure 9: Insertion of compression screw

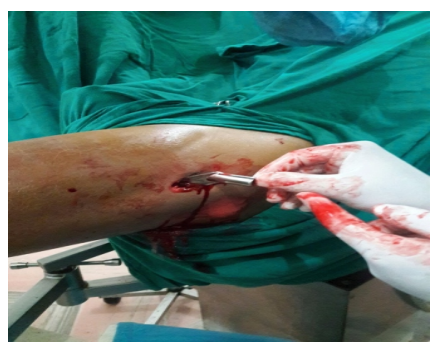

Figure 8: Insertion of barrel plate

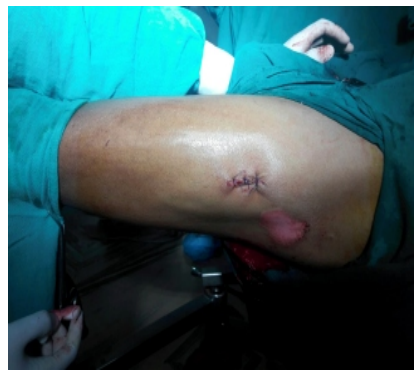

Figure 10: Skin Closer
Duration of surgery was noted. Intra operative blood loss was measured. Hemoglobin level was checked on the first postoperative day. Epidural analgesia with mixture of $1 \mathrm{mg}$ preservative free morphine and $0.125 \%$ bupivacaine diluted with Normal Saline to make total volume of $10 \mathrm{ml}$ was given for post-operative pain 12 hourly through Lumber Epidural Catheter by Anesthesia team till $3^{\text {rd }}$ postoperative day. First dose of epidural analgesia was given at the time of skin closure. Injection Paracetamol 1 gram intravenously over half an hour was given for rescue analgesia on patient's demand. Total days of hospital stay and any complication recorded in the patient's file was noted. Post-operative radiography was reviewed for evaluation of fracture reduction and screw position(Figure 11\&12).

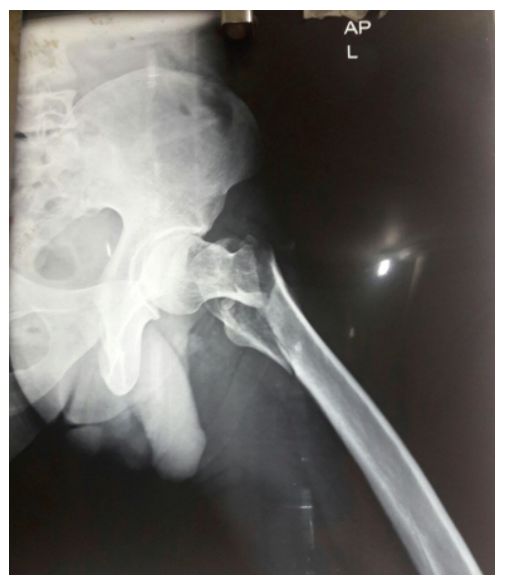

Figure 11: Preoperative X-ray of Pelvis

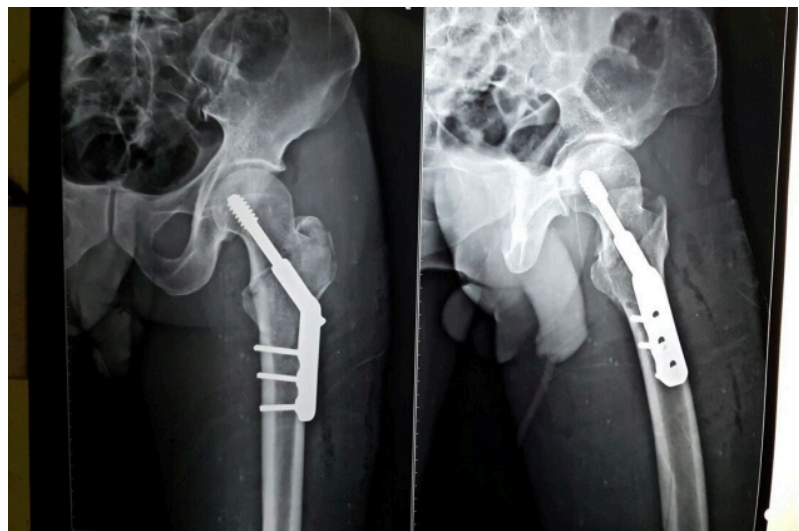

Figure 12: Postoperative X-ray of Pelvis

All patients were reviewed on $6^{\text {th }}, 12^{\text {th }}, 24^{\text {th }} \& 48^{\text {th }}$ week. Both clinical and radiological evaluation was done. Functional outcome of the operated hip joint was evaluated by calculating Harris Hip Score during follow up visits. Pain, function, deformity, range of motion and limb length discrepancy were noted and scored accordingly. ${ }^{10}$

\section{RESULTS:}

Records of 66 patients underwent MIDHS fixation for intertrochanteric fracture with 1 year follow up were studied, among which 38 patients were male and 28 were female with mean age 69.17 years ranging from 40 to 92 years. 42 fractures were in right side and 24 in left.

The highest rate of fracture was seen in age group between 7080 years, accounted for $33.33 \%$. The incidence of the injury was high among farmer which was $47 \%$ and housewife which was also $31.8 \%$. The records also showed $65.2 \%$ (43 cases) patients sustained fractures due to slippage on ground, $21.2 \%$ (14 cases) patients sustained fractures due to road traffic accident (RTA) and only $13.6 \%$ (9 cases) sustained fracture due to fall from height.

Mean operating time was 42.88 minutes ranging from 30-60 minutes. Mean wound size, perioperative blood loss and reduction in post operative haemoglobin as compared to baseline value was $4 \mathrm{~cm}, 122.12 \mathrm{ml}$ and $1.53 \mathrm{gm} / \mathrm{dl}$ respectively.

All patients were ambulated within $2^{\text {nd }}$ postoperative day. Rescue analgesic was demanded by 8 patients especially after $4^{\text {th }}$ postoperative day. The mean duration of hospital stay was 8.23days (5-14 days). Stitch infection and Urinary tract infection was seen in 4 and 2 patients respectively. None of these patients showed nausea and vomiting, pruritus, constipation, dizziness and respiratory depression in postoperative period. There were no any records of 
complications like bed sores, plate breakage, implant cut out, joint infection, delayed union, varus deformity and stiffness in any of these patients. The functional status measured according to Harris Hip Score system at $6^{\text {th }} \& 12^{\text {th }}$ postoperative month was 80 and 90 respectively.

\section{DISCUSSION:}

Hip fractures are leading cause of death and disability among the elderly. Incidence of trochanteric fracture increases with age because of increased average life expectancy. The fractures of the proximal part of femur have been marked as one of the biggest problems of the society and trochanteric fractures are around four times more frequent than the fractures of the proximal part of the femur. Treatment goals for this patients population includes early rehabilitation, restoration of the anatomic alignment of the proximal part of femur and maintenance of fracture reduction.

In our study, the mean age of the patient was $69.17 \mathrm{yrs}$ and the highest incidence $(33.33 \%)$ of injury was seen among the age group of 70 to 80 due to poor vision, osteoporotic bone quality, menopausal ladies, slippery mud and negligence by the family members as noted by history. Various studies also showed mean age more than 60 years ${ }^{11-14}$. Around $58 \%$ patients were male and $42 \%$ were female. Male preponderance might be due to more activity and mobility as compared to females who mostly confined to household activities in our country and thus are less prone to sustain an extra capsular fracture of hip. In contrast, few studies showed female predominance. Also, Melton JL et al. mentioned that the annual rate of intertrochanteric fractures in elderly female was about 63 per 100,000 while in male was 34 per 100,000 in United States. ${ }^{15}$

Slightly longer mean operating time of 43mins for MIDHS in our study can be explained by difficulty in barrel plate manipulation to fit the inserted lag screw through smaller incision when compared to study done by Michael et al. which showed mean operating time of 39 minutes whereas other studies showed mean operating time of more than 55 minutes. ${ }^{16-18}$ Similarly, mean intraoperative blood loss was only $122 \mathrm{ml}$ in our study but it ranges from $225 \mathrm{ml}$ to $495 \mathrm{ml}$ in various studies. $^{19-23}$

Angiographic study of the proximal femur revealed that the distance from the Vastus Lateralis ridge to the first branch is from 8 to $9.3 \mathrm{~cm}$ and thus, is considered as safe vascular zone for the minimally invasive DHS technique where a $35 \mathrm{~cm}$ incision is made and the proximal site of the incision is approximately 3 to $4 \mathrm{~cm}$ below this ridge. Therefore, blood loss in our study is minimal as compared to other studies with less tissue dissection for fracture exposure. ${ }^{24-26}$

Reduction in postoperative haemoglobin was also insignificant when compared preoperative haemoglobin value with the haemoglobin value of $1^{\text {st }}$ postoperative day. Out of 66 patients, 59 patients were operated by DHS with 3 holes barrel plate and 7 patients were operated with DHS with 4 holes barrel plate. Previous biomechanical studies have shown no advantage of four screws over three. Study done by Yian et al. also concluded that three bone screws provide an optimal distribution of tensile force. ${ }^{27}$ Several authors have reported the use of two-hole side plate and produce satisfactory healing. ${ }^{28,29}$ Also, mean days of hospital stay in our study was much lesser when compared with study done by Michael Ho (8 days vs 13.5 days). ${ }^{16}$

Our study did not show any significant early complications except mild to moderate pain, stitch and urinary tract infections which is almost similar to the study conducted by Islam KM et. ${ }^{30}$ Only 8 patients required rescue analgesia on their demand mainly after $4^{\text {th }}$ postoperative day. Analgesic demands might be because of removal of epidural catheter on $3^{\text {rd }}$ postoperative day.

Fracture that occurs through highly vascular cancellous bone usually heals within 8 to 12 weeks regardless of method of treatment, in almost all cases. ${ }^{4}$ In the study conducted by Leung $\mathrm{W}$ et al., mean bone healing time was 9 weeks whereas another study showed complete fracture union occurred in average 4.2 months. ${ }^{31,32}$ In our study, mean union time was 14 weeks and it might be due to decrease drainage of fracture haematoma through small incision $(<5 \mathrm{~cm})$ during surgery supporting biological process of fracture healing. Hence, early fracture healing and enhanced union rates.

Union of fracture was associated with early mobilization by toe movement and quadriceps exercises which begun on $1^{\text {st }}$ postoperative day. Sitting and knee range of motion exercises begun on $2^{\text {nd }}$ postoperative day which increased micro movements at the fracture site and enhances the union rate. Partial weight bearing was started on mean 5.7 weeks and full weight bearing was started on mean duration of 11.02 weeks, which further enhanced rate of union. Sliding of the lag screw in the barrel allows the fracture to collapse impacting the stable position. It provides controlled compression at the fracture which further enhances the union rate. Also, the functional status of our patient according to Harris Hip Score system at $6^{\text {th }}$ and $12^{\text {th }}$ postoperative month was found to be "Good" which is almost similar to various other studies.

\section{CONCLUSION:}

Minimal invasive DHS fixation technique for intertro chanteric fracture under epidural analgesia results in decreased hospital stay and cost, less incidence of complications with good functional outcome. 


\section{REFERENCES :}

1. Larsson S, Friberg S, Hansson LI; Trochanteric fractures: mobility, complications, and mortality in 607 cases treated with the sliding-screw technique; Ortho Clin. 1990; 260:232-41

2. Apel DM, Patwardhan A, Pinzur MS, Dobozi WR; Axial loading studies of unstable intertrochanteric fractures of the femur. Orthop Clin. 1989; 246:156-63

3. Brumgaertner MR, Curtin SL, Lindskog DM; The value of the tip apex distance in predicting failure of fixation of pertrochanteric fractures of hip; J Bone joint Surg. 1991; 77A:1058-64.

4. Ganz R, Thomas RJ, Hammerle CP; Trochanteric fractures of femur: treatment and results. Orthop Clin. 1979; 138: 30-40

5. Baixauli F, Vicent V, Baixauli E, Serra V, Sanchez-Alepuz E, Gomez V, et al; A reinforced rigid fixation device for unstable intertrochanteric fractures. Clin Orth Op Relat Res 1999; 361:20515

6. Watson JT, Moed BR, Cramer KE, Karges DE; Comparison of the compression hip screw with the Medoff sliding plate for intertrochanteric fractures. Clin Orthop Relat Res 1998; 348:7986

7. Fogagnolo F, Kfuri M Jr. Paccola CA; Intramedullary fixation of pertrochanteric hip fractures with the short AO-ASIF proximal femoral nail. Arch Orthop Trauma Surg 2004; 124:317

8. Jabshetty $A B$. Management of intertrochanteric fracture by DHSfixation. Indj sci tech 2014; 4:1681-84

9. Leung KS, So WS, Shen WY, Hui PW; Gamma nails and dynamic hip screws for peri-trochanteric fractures, A randomized prospective study in elderly patients; J Bone Joint Surg Br 1992; 74:34551.

10. Harris hip score, Harris WH; JBJS 1969; 51

11. Christian Boldin, Franz J Seibert, Florian Fankhauser, Gerolf Peicha, Wolfgang Grechenig \& Rudolf Szyszkowitz (2003); The proximal femoral nail (PFN) - a minimal invasive treatment of unstable proximal femoral fractures: A prospective study of 55 patients with a follow-up of 15 months, Acta Orthopaedica Scandinavica, 74:1, 53-58, DOI: 10.1080/ 00016470310013 662

12. Bridle $S H$, Patel AD, Bircher $M$, et al; Fixation of intertrochanteric fractures of the femur. A randomised prospective comparison of the gamma nail and the dynamic hip screw, The Bone \& Joint Journal April 1991; 73(2):330-4

13. Sudan M, Sadowski C et al; Peritrochanteric fractures. Is there an advantage of intramedullary nail? ; J Orthop Trauma 2002; 16: 386393

14. LeungWy, Tsang Wl; Conventional muscle-reflection approach vs mini-incision muscle-splitting approachin DHS fixation; $j$ orthosur 2008; 16(2):156-6
15. L. Joseph Melton III, Heinz W. Wahner, Linda S. Richelson, W. Michael O'fallon and B. Lawrence Riggs: Osteoporosis And The Risk Of Hip Fracture; Oxford Journals, Medicine \& Health, American Jnl of Epidemiology, Volume 124, Issue 2 Pp. 254-261

16. Michael Ho, Giorgio Garau, Gayle Walley, Francesco Oliva, Alfredo Schiavone Panni, Umile Giuseppe Longo, and Nicola Maffulli; Minimally invasive dynamic hip screw for fixation of hip fractures; Int Orthop. 2009 Apr; 33(2): 555560

17. Waters TS, Gibbs DMR, Dorrell JH, Powles DP; Percutaneous dynamic hip screw, Injury 2006; 37(8):751-4

18. Wang JP, Yang TF, Kong $O Q$, et al; Minimally invasive technique versus conventional technique of dynamic hip screws for intertrochanteric femoral fractures; Arch Orthop Trauma Surg. 2010; 130(5):613620

19. Pan X, Xiao D, Lin B, Huang G; Dynamic hip screws (DHS) and proximal femoral nails $(P F N)$ in treatment of intertrochanteric fractures of femur in elderly patients. Chinese Journal of Orthopaedic Trauma.2004; 6(7):785789

20. J. Pajarinen, J. Lindahl, O. Michelsson, V. Savolainen, and E. Hirvensalo; "Pertrochanteric femoral fractures treated with a dynamic hip screw or a proximal femoral nail: a randomised study comparing post-operative rehabilitation; Journal of Bone and Joint Surgery 2005;87 (1) 7681

21. B. Giraud, E. Dehoux, N. Jovenin, et al ; Comparaison visplaque dynamique et ostéosynthèse antérograde dans les fractures pertrochantériennes'Rev Chir Orthop, (2005) ; 91; 732736

22. S. Papasimos, C.M. Koutsojannis, A. Panagopoulos, et al ; A randomised comparison of $A M B I, T G N$ and $P F N$ for treatment of unstable trochanteric fractures; Arch Orthop Trauma Surg, $2005 ; 125 ; 462468$

23. Huang $Z Y$, Liu $X W$, Su JC; Dynamic hip screw vs. proximal femur nail in treatment of intertrochanteric fractures in patients aged over 70 years old. Shanghai Medical Journal. 2010; $33(11): 1042$

24. Zhou Z, Zhang X, Tian S, Wu Y; Minimally invasive versus conventional dynamic hip screw for the treatment of intertrochanteric fractures in older patients. Orthopedics 2012;35(2):e2449

25. Waters TS, Gibbs DMR, Dorrell JH, Powles DP ; Percutaneous dynamic hip screw. Injury 2006;37(8):7514

26. Alobaid A, Harvey EJ, Elder GM, Lander P, Guy P, Reindl R: Minimally invasive dynamic hip screw: prospective randomized trial of two techniques of insertion of a standard dynamic fixation device; JOrthop Trauma 2004;18(4):20712

27. Yian EH, Banerji I, Matthews LS; Optimal side plate fixation for unstable intertrochanteric hip fractures.J Orthop Trauma. 1997; 11:2549

28. Alobaid A, Harry EJ, Elder GM et al ; Prospective randomized trial of two techniques of insertion of a standard dynamic fixation device. JOrthop Trauma 2004;18(4):207212 
29. Bolhofner B, Russo P, Carmen B ;Results of intertrochanteric femur fractures treated with a 135-degree sliding screw with a two-hole side plate. JOrthop Trauma 1999;13:58

30. Islam KM, Alam M, Mahmud AA, Ahammed S; Evaluation of the result of dynamic hip screw fixation in unstable trochanteric fracture of femur; The ORION Medical Journal 2007 May; $27: 458-462$

31. Leung WY, Tsang WL; Conventional muscle-reflection approach vs mini-incision muscle-splitting approach in DHS fixation; $j$ orthosur 2008; 16(2):156-61

32. A. shams, M. Elsawy, M. el-sayed, K. hafez, H. Gad; Comparitive, prospective, randomized, study of the modified minimally invasive technique versus the conventional technique of DHS fixation of IT fracture in elderly patients; Eurorthop, Traumatol; 2014:014-027
33. Ujjal Bhakat, Ranadeb Bandyopadhayay; Comparitive Study between Proximal Femoral Nailing and Dynamic Hip Screw in Intertrochanteric Fracture of Femur; Open Journal of Orthopedics, 2013, 3, 291-295

34. Wong TC, Chiu Y, Tsang WL, Leung WY, Yeung SH; A double blind, prospective, randomized, controlled clinical trial of minimally invasive dynamic hip screw fixation of intertrochanteric fractures; Injury 2009; 40(4):422-7

35. Yih Shiunn Lee, Hui Ling Huang, Ting Ying Lo, Chien Rae Huang; Dynamic hip screw in the treatment of intertrochanteric fractures: a comparision of two fixation methods; International Orthopaedic 2007 31: 683-88 